\title{
Improving classification based on physical surface tension- neural net for the prediction of psychosocial-risk level in public school teachers
}

\author{
Rodolfo Mosquera-Navarro ${ }^{\text {Corresp., } 1,2}$, Omar Danilo Castrillón ${ }^{3}$, Liliana Parra-Osorio ${ }^{4}$, Tiago Oliveira ${ }^{5}$, Paulo Novais ${ }^{6}$ \\ , José Fernando Valencia ${ }^{7}$ \\ 1 Departamento de Ingeniería Industrial, Universidad Nacional de Colombia, Manizales, Caldas, Colombia \\ 3 Departmento de Ingeniería Industrial, Universidad Nacional de Colombia, Manizales, Caldas, Colombia \\ ${ }^{4}$ Centro de Investigaciones Socio jurídicas, Facultad de Derecho, Universidad Libre, Bogotá, Cundinamarca, Colombia \\ 5 Algoritmi Center, Universidade do Minho, Minho, Braga, Portugal \\ 6 Department of Informatics/Algoritmi Center, Universidade do Minho, Minho, Braga, Portugal \\ 7 Department of Ciencias y Tecnologías de la Información, Universidad de San Buenaventura - Cali, Cali, Valle del Cauca, Colombia
}

Corresponding Author: Rodolfo Mosquera-Navarro

Email address: rmosqueran@usbcali.edu.co

Background. Psychosocial risks, also present in educational processes, are stress factors particularly critical in state-schools, affecting the efficacy, stress, and job satisfaction of the teachers. This study proposes an intelligent algorithm to improve the prediction of psychosocial risk, as a tool for the generation of health and risk prevention assistance programs. Methods. The proposed approach, Physical Surface Tension-Neural Net (PST$N N)$, applied the theory of superficial tension in liquids to an artificial neural network (ANN), in order to model four risk levels (low, medium, high and very high psychosocial risk). The model was trained and tested using the results of tests for measurement of the psychosocial risk levels of 5,443 teachers. Psychosocial, and also physiological and musculoskeletal symptoms, factors were included as inputs of the model. The classification efficiency of the PST-NN approach was evaluated by using the sensitivity, specificity, accuracy and ROC curve metrics, and compared against other techniques as Decision Tree model, Naïve Bayes, ANN, Support Vector Machines, Robust Linear Regression and Logistic Regression Model. Results. The modification of the ANN model, by the adaptation of a layer that includes concepts related to the theory of physical surface tension, improved the separation of the subjects according to the risk level group, as a function of the mass and perimeter outputs. Indeed, the PST-NN model showed better performance to classify psychosocial risk level on state-school teachers than the linear, probabilistic and logistic models included in this study, obtaining an average accuracy value of $97.31 \%$.

Conclusions. The introduction of physical models, such as the physical surface tension, 
can improve the classification performance of ANN. Particularly, the PST-NN model can be used to predict and classify psychosocial risk levels among state-school teachers at work. This model could help to early identification of psychosocial risk and to the development of programs to prevent it. 
1 Improving Classification based on Physical Surface Tension-Neural Net

2 for the Prediction of Psychosocial-risk Level in Public School Teachers

3

4 Rodolfo Mosquera-Navarro ${ }^{1,2 *}$, Omar Danilo Castrillón ${ }^{2}$, Liliana Parra-Osorio ${ }^{3}$, Tiago

5 Oliveira ${ }^{4}$ Paulo Novais ${ }^{5}$ and José Fernando Valencia ${ }^{6}$

7

${ }^{1}$ Grupo Nuevas tecnologías trabajo y gestión, Universidad de San Buenaventura, Cali, Valle del Cauca, Colombia 2Departamento de Ingeniería Industrial, Universidad Nacional de Colombia, Manizales, Caldas, Colombia

${ }^{3}$ Centro de Investigaciones Socio jurídicas, Facultad de Derecho, Universidad Libre, Bogotá, Cundinamarca, Colombia.

${ }^{4}$ Algoritmi Center, Universidade do Minho, Minho, Braga, Portugal.

${ }^{5}$ Department of Informatics/Algoritmi Center, Universidade do Minho, Minho, Braga, Portugal.

${ }^{6}$ Department of Ciencias y Tecnologías de la Información, Universidad de San Buenaventura, Cali, Valle del Cauca, Colombia.

Corresponding Author:

Rodolfo Mosquera Navarro ${ }^{1}$

Carrera 122 \# 6-65, Cali, Valle del Cauca, 760031, Colombia.

Email address: rmosqueran@usbcali.edu.co 
Background. Psychosocial risks, also present in educational processes, are stress factors particularly critical in state-schools, affecting the efficacy, stress, and job satisfaction of the teachers. This study proposes an intelligent algorithm to improve the prediction of psychosocial risk, as a tool for the generation of health and risk prevention assistance programs.

Methods. The proposed approach, Physical Surface Tension-Neural Net (PST-NN), applied the theory of superficial tension in liquids to an artificial neural network (ANN), in order to model four risk levels (low, medium, high and very high psychosocial risk). The model was trained and tested using the results of tests for measurement of the psychosocial risk levels of 5,443 teachers. Psychosocial, and also physiological and musculoskeletal symptoms, factors were included as inputs of the model. The classification efficiency of the PST-NN approach was evaluated by using the sensitivity, specificity, accuracy and ROC curve metrics, and compared against other techniques as Decision Tree model, Naïve Bayes, ANN, Support Vector Machines, Robust Linear Regression and Logistic Regression Model.

Results. The modification of the ANN model, by the adaptation of a layer that includes concepts related to the theory of physical surface tension, improved the separation of the subjects according to the risk level group, as a function of the mass and perimeter outputs. Indeed, the PST-NN model showed better performance to classify psychosocial risk level on state-school teachers than the linear, probabilistic and logistic models included in this study, obtaining an average accuracy value of $97.31 \%$.

Conclusions. The introduction of physical models, such as the physical surface tension, can improve the classification performance of ANN. Particularly, the PST-NN model can be used to predict and classify psychosocial risk levels among state-school teachers at work. This model could help to early identification of psychosocial risk and to the development of programs to prevent it. 
67 Introduction

68

69

70

71

72

73

74

75

76

77

78

79

80

81

82

83

84

85

86

87

88

89

90

91

92

93

94

95

96

97

98

99

100

101

102

103

104

105

106

107

108

109

110

111

Psychosocial risks are stress factors that can alter and unbalance a person's resources and abilities to manage and respond to a flow of work activity, negatively affecting physical and psychological health (Sauter \& Murphy, 1984). Among initial prediction models that enable identification of risks associated with work-related stress (Karasek, 1979) and workplace variables, some are based on mental stress resulting from workplace demands and decision-making. Workplace variables may cause the worker to feel their effort is inadequate, in accordance with the compensation obtained therefrom, and contribute to the development of work-related stress (Siegrist, 1996).

This situation is particularly critical in state-schools teachers, where work-related stress are present in educational processes (Kinman, 2001). A previous study (Collie, Shapka \& Perry, 2012) shows how teachers' perception of their work environment influence levels of: teaching efficacy, stress, and job satisfaction. The study demonstrates that the teachers' perceptions of students' motivation and behavior have the highest risk level. Workplace variables directly impact the perception of well-being among participants. Stress is negatively associated with the teaching efficacy variable. Additionally, stress influences directly on sense of job satisfaction, workload, and teaching efficiency. Indeed, prediction of psychosocial risk levels in state-school teachers is fundamentally important as a tool for the generation of health and risk prevention assistance programs.

Similar studies, focused on population different from teachers, have used machine learning techniques as Dynamic Bayesian Networks (DBN), Logistic Regression, Support Vector Machine, and Naïve Bayes classifiers(Wenhui Liao et al., 2005; Subhani et al., 2017), to attempt a recognition of the patterns associated with workplace stress and for the detection of mental stress at two or multiple levels. Variables as facial expressions, eye movements, physiological conditions, behavioral data from activities in which users interact with the computer, and performance measurement, have been considered in that previous studies. A high level of stress is associated with symptoms including rapid heartbeat, rapid breathing, increased sweating, cold skin, cold hands and feet, nausea, and tense muscles, among others. Accuracy of $94.6 \%$ for two-level identification of stress and $83.4 \%$ accuracy for multiple level identifications have been reported.

Artificial neural networks (ANN) are a classification technique that in recent years have regained importance thanks to improvements associated with technology, as the deep learning (Saidatul et al., 2011; Sali et al., 2013). One of the crucial components of deep learning are the neural network activation functions, which are mathematical equations that determine the output of the ANN model, its accuracy, and also the computational efficiency. Different linear and nonlinear activation functions have been proposed in the literature (Tzeng, Hsieh \& Lin, 2004), each one with its advantages and disadvantages, but reporting a better performance when nonlinear mathematical equations are included. The present work introduces a novel approach based on a modification in the activation function of the neural network, based on the theory of surface tension, in order to optimize the convergence of solutions in the classification processes. Indeed, the neural network calculates the desired output, using the surface tension function instead of the sigmoid function. In terms of mass and perimeter, these two surface tension equation parameters 
112 intervene to replace the network sigmoid function, with the aim to reduce data variability and dimensionality, and to improve the response in the classification and resulting error.

In the present study, the development of an new approach of neural network, based on Physical Surface Tension (Jasper, 1972) to model and predict psychosocial risk levels among Colombian state-school teachers, is presented. The Physical Surface TensionNeural Net (PST-NN) approach is applied to psychosocial factors, musculoskeletal and physiological variables, present in academic environments in state-schools, in order to recognize their patterns, and thereby predict the type of risk to which a new individual may be exposed in such a work environment.

The next part of the document is organized as follows: first, the database, the preprocessing of the data, the definition of the new PST-NN approach, and the applied statistical tests, are described in Materials \& Methods section; then, the Results section contains information about the training and test of the PST-NN approach, and its comparison with other published techniques; finally, the results are discussed and concluded in Discussion and Conclusions sections.

\section{Materials \& Methods}

In this study, the results of tests for measurement of the psychosocial risk levels of 5,443 teachers, in five Colombian state-schools in cities in the same area, were analyzed. The data were obtained over a period of one and a half years. The dataset is a selfadministered survey by labor psychologist and it was approved by university ethics committee public health at Universidad Nacional de Colombia, campus Manizales (Acta 01, SFIA-0038-17, legal document Mz. ACIOL-009-17, January 18, 2017). The dataset can be consulted in https://zenodo.org/record/1298610 (Mosquera, Castrillón Gómez \& ParraOsorio, 2018).

\section{Database and Data Pre-processing}

The dataset contains information about the following variables: i) psychosocial; ii) physiological, and; iii) variables associated with pain and musculoskeletal disorders. Psychosocial risk factors may be separated into two main classes: those which have negative effects on health, and those which contribute positively to the worker's well-being. Although both are present in all work environments, the present study considered those which negatively affect health in academic public-schools organizations (El-Batawi, 1988; Bruhn \& Frick, 2011; Lippel \& Quinlan, 2011; Weissbrodt \& Giauque, 2017; Dediu, Leka \& Jain, 2018).

Among the risk factor variables associated with work environment analysis, there was a total of 131 input variables: $X_{i j}=$ (psychosocial factors, $\left.j=1, \ldots, 123\right), P_{i j}=$ (physiological factors, $j=1, \ldots 3$ ) and $M_{i j}=$ (musculoskeletal symptoms, $j=1, \ldots 5$ ), where, $i$ is the subject under study. Output variables were identified as the level of risk in which the person may be characterized $E_{i j}=$ Class [low risk $\left(E_{1}\right)$, medium risk $\left(E_{2}\right)$, high risk $\left(E_{3}\right)$, and very high 
154

155

156

157

158

159

160

161

162

163

164

165

166

167

168

169

170

171

172

173

174

175

176

177

178

risk $\left(E_{4}\right)$ ]. Surface electromyography was performed to corroborate the musculoskeletal problems declared in patients with level of risk medium, high and very high, and confirmed in their clinical history. Electromyography data were collected with a BITalino ( $r$ )evolution Plugged kit (PLUX Wireless Biosignals S.A, Lisbon, Portugal) and validated by a medical specialist to find out if the patients actually had osteomuscular problems.

Redundant psychosocial factors $\left(X_{i j}\right)$ were filtered by means of rank importance of predictors using ReliefF algorithm procedure (1) (Robnik-S \& Kononenko, 2003), with the goal of identifying noisy variables in the dataset using the Chebyshev metric criteria. The ReliefF algorithm located important predictors throughout the 10 nearest neighbors and put the $123 X_{i j}$ independent factors into groups. Predictor numbers were listed by ranking, and the algorithm selected the predictors of greatest importance. The weights yielded weight values in the same order as that of the predictors. Distances between factor pairs, at this weight, were measured once again, and the factor with the lowest total value (distance) was chosen, which yielded $12 X_{i j}$ factors per group. It further added physiological $\left(P_{i j}\right)$ and musculoskeletal symptom variables $\left(M_{i j}\right)$. The algorithm recognized the variables with the lowest value and punished those predictors (risk associated with each individual $X_{i r}$, where $r=1, \ldots 4$ represents the risk level: low risk $\left(X_{i 1}\right)$, medium risk $\left(X_{i 2}\right)$, high risk $\left(X_{i 3}\right)$, and very high risk $\left(X_{i 4}\right)$ ), which produced different values for neighbors in the same group (risk factors group $F_{i j}$, and it increased those which produce different values for neighbors in different groups. ReliefF initially defined predictor weights $R_{i j}$ at 0 , and the algorithm subsequently selected a random value $X_{i r}$, iteratively. The k-nearest values $X_{i r}$ for each group were identified, and all predictor weights $F_{i j}$ for the nearest neighbors $X_{i q}$ were updated (Robnik$S^{\sim}$ \& Kononenko, 2003, p. 26).

$$
\text { "W[A]:=W[A]- } \sum_{j=1}^{k} \frac{\operatorname{diff}\left(A, R_{i}, H_{j}\right)}{m \cdot k}+\sum C \neq \operatorname{class}\left(R_{i}\right)+\left[\frac{P(C)}{1-P\left(\operatorname{class}\left(R_{i}\right)\right)} \sum_{j=1}^{k} \frac{\left.\operatorname{diff}\left(A, R_{i}, M_{j}(C)\right)\right]}{m \cdot k} "\right.
$$

Where,

$R_{i}$ is randomly selected instances.

$H_{i}$ is $\mathrm{k}$ nearest hits (k-nn with the same class).

$M_{j}(C)$ is k nearest misses (k-nn with the different class).

$W[A]$ is the quality estimation for all attributes $\mathrm{A}$ for $\mathrm{Ri}$, and $\mathrm{Hj}$ and misses values $\operatorname{Mj}(C)$.

$1-P\left(\operatorname{class}\left(R_{i}\right)\right)$ is the sum of probabilities for the misses classes.

$m$ is the processing time repeated.

In total, 20 input variables $E_{i j}=X_{i j}+P_{i j}+M_{i j}$ were selected (Tables $1-3$ ): twelve variables $X_{i j}=(j=1, \ldots, 12)$, which constituted psychosocial variables; three physiological variables $P_{i j}=(j=1, \ldots 3)$, and; five variables associated with musculoskeletal symptoms $M_{i j}=(j=1$, ...5). This variables were normalized, in accordance with Equation 2. 


$$
E_{\text {normalized }}=\frac{\left(E-E_{\text {min }}\right)}{E_{\text {max }}-E_{\min }}
$$

192

193

194

195

196

197

198

199

200

201

202

203

204

205

206

207

208

209

210

211

212

213

214

215

216

217

218

219

220

221

222

223

224

225

226

227

Where, $E$ corresponds to the variable to be normalized, $E_{\max }$ is the maximum value of each variable, $E_{\min }$ is the minimum value, and $E_{\text {normalized }}$ is the normalized variable within the -1 to 1 range.

\section{Basis of the surface tension-neural net algorithm (PST-NN)}

The approach was based on the theory of liquid surface tension (Macleod, 1923; Jasper, 1972; Tyson \& Miller, 1977), given by equation 3. Liquid surface tension is defined as the amount of energy necessary to increase surface area of a liquid per unit of area. Surface tension (a manifestation of liquid intermolecular forces) is the force that tangentially acts, per unit of longitude, on the border of a free surface of a liquid in equilibrium, and which tends to contract the said surface (Adamson \& Gast, 1967a). The cohesive forces between liquid molecules are responsible for a phenomenon known as surface tension (Fowkes, 1962; Adamson \& Gast, 1967b; Lida \& Guthrie, 1993; Law, Zhao \& Strojnisìtva., 2016; Almeida et al., 2016).

$$
\gamma=\frac{F}{2 L}
$$

Where, $\gamma$ is the surface tension that measures the force per unit length (in the model $\gamma$ is the classification risk level), $F$ is the force required to stop the side from starting to slide, $L$ the length of the movable side, and the reason for the $1 / 2$ is that the film has two surfaces (Macleod, 1923). In this model, the multiplication of the perimeter of an object by the surface tension of a liquid yields the force that a liquid exerts on its surface, on an object, in order to prevent said tension from breaking. As such, if the weight of an object is greater than the force exerted by the liquid on its surface, the object tends to sink.

The theory of surface tension addresses cohesion between molecules in a liquid, and their energetic relationship with the exterior, generally a gas. When submitted to a force that breaks the energetic state of molecular cohesion, the surface of a liquid causes the object producing internal force in the liquid to sink. This proposal sought to emulate the surface tension theory in the psychosocial analysis of risk factors present in work environments and their degrees of risk, from the viewpoint of improving a machine learning model. It used and adapted the said theory to improve risk classification and modify the necessary parameters of a neural network (the number of layers, nodes, weights, and thresholds) to reduce data dimensionality, and increase precision.

\section{Implementation of the PST-NN algorithm}

The 20 input variables $E_{i j}$ became two physical variables, perimeter and mass, throughout an artificial neural network with four layers. Three of these layers constitute 
228

229

230

231

232

233

234

235

236

237

238

239

240

241

242

243

244

245

246

247

248

249

250

251

252

253

254

255

256

257

258

the architecture of a standard neural network, with the difference that, the last level contains a new neural network model based on physical surface tension (Adamson \& Gast, 1967b). Eighty neurons were used in layers one and two, due to the fact that substantial changes were not registered using more neurons in these layers . Additionally, just two neurons were used for layer 3, in order to annex the new proposed surface tension layer. The architecture of the artificial neural classification network is shown in Fig. 1. This included the three standard neuron layers, as well as a fourth layer with a novel design.

For the initialization of the neural network parameters, the Nguyen-Widrom algorithm was used (Pavelka \& Prochazka, 2004; Andayani et al., 2017), in which random parameters were generated. However, the advantage of this was that the parameters distribute the active neural regions much more uniformly in layers, which improved neural network training, as it presented a lower learning rate error from the beginning.

Layer 1 output calculation: The 20 input variables of a specific individual from the training set, a vector called $\boldsymbol{E}$, went through an initial layer of 80 neurons. Each neuron had 20 parameters, called weights, which multiplied each input variable of vector $\boldsymbol{E}$. A parameter called bias $\boldsymbol{b}$ was added to this multiplication. It was associated with each neuron, which results in the partial output of Layer 1 . This procedure is described throughout the following equation:

$$
y_{k}{ }^{1}=\left(\sum_{i=1}^{20} E_{i} * w_{k, i}{ }^{1}\right)+b_{k}^{1} \text { for } k=1 \text { to } 80
$$

$$
y^{1}=\left\{y_{1}^{1}, y_{2}^{1} \ldots y_{80}^{1}\right\}
$$

Where $\boldsymbol{E}_{\boldsymbol{i}}$ is the i variable of the individual chosen from the training set, $\boldsymbol{w}_{\boldsymbol{k}, \boldsymbol{i}} \mathbf{1}$ is the $k$ neuron's weight in Layer 1 , which is multiplied by variable i, $\boldsymbol{b}_{\boldsymbol{k}}{ }^{\mathbf{1}}$ is neuron k's bias in Layer 1 , which is added to the total, and $y_{k}{ }^{1}$ is the result of each $k$ neuron. These 80 results were represented by $y^{\mathbf{1}}$ vector, and $y^{\mathbf{1}}$ went through a hyperbolic tangent transfer function, as this is a continuous transfer function, and is recommended for patternrecognition processes(Harrington, 1993).

Layer 1 output is described in the following equation

$$
Y_{k}^{1}=\frac{2}{1+e^{-2 * y_{k}^{1}}-1 \text { for } k=1 \text { to } 80}
$$

$$
Y^{1}=\left\{Y_{1}^{1}, Y_{2}^{1} \ldots Y_{80}^{1}\right\}
$$

Where, $e$ is the exponential function and $\boldsymbol{Y}^{\mathbf{1}}$ is the final output for Layer 1 and is composed of 80 outputs, one for each neuron. 
Layer 2 output calculation: The 80 outputs from Layer $1, \boldsymbol{Y}^{\mathbf{1}}$, became the inputs for the procedure performed in Layer 1, the following equations were obtained:

$$
y_{k}^{2}=\left(\sum_{i=1}^{80} Y_{i}^{1} * w_{k, i}{ }^{2}\right)+b_{k}^{2} \text { for } k=1 \text { to } 80
$$

re $Y_{i}{ }^{1}$ is the output of neuron i from Layer $1, w_{k, i}{ }^{2}$ is the weight of neuron $k$, associated with the output of neuron $i$ in Layer $1, b_{k}{ }^{2}$ is neuron $k$ 's bias in Layer 2 , and $y^{2}$ includes the 80 responses of each neuron, prior to passing through the transfer function. In order to obtain the final output for Layer $2\left(Y^{2}\right)$ the hyperbolic transfer function was applied: $Y_{k}^{2}=\frac{2}{1+e^{-2 * y_{k}{ }^{2}}}-1$ for $k=1$ to 80

263

$$
Y^{2}=\left\{Y_{1}^{2}, Y_{2}^{2} \cdots Y_{80}^{2}\right\}
$$

264

267

$$
Y_{k}^{3}=\left(\sum_{i=1}^{80} Y_{i}{ }^{2} * w_{k, i}{ }^{3}\right)+b_{k}{ }^{3} \text { for } k=1 \text { to } 2
$$

268

$$
Y^{3}=\left\{Y_{1}{ }^{3}, Y_{2}{ }^{3}\right\}=\{m, P e r\}
$$

Where $Y_{i}^{2}$ is the output of neuron i in Layer $2, w_{k, i}{ }^{3}$ is the weight of neuron $k$ in Layer 3 , which multiplies the output of neuron i in Layer 2 , and $Y_{k}{ }^{3}$ is the final output of each of the two neurons represented in vector $Y^{3}$. In the approach of Physical Surface Tension Neural Net (PST-NN), these two output variables were then considered mass $(m)$ and perimeter (Per), respectively, which went into a final layer called the surface tension layer. This was composed of four neurons, one neuron for each risk level. Each of these contributed to a balance of power defined by the following equation:

Where, 


$$
O_{k}=1-e^{\frac{-m * g}{T_{k} * P e r}} \text { for } k=1 \text { to } 4
$$

277

$$
\boldsymbol{O}=\left\{\boldsymbol{O}_{1}, \boldsymbol{O}_{2}, \boldsymbol{O}_{3}, \boldsymbol{O}_{4}\right\}
$$

With:

$$
T_{k}=\{22.1 ; 47.7 ; 72.8 ; 425.41\}
$$

279

280

281

282

283

284

285

286

287

288

289

290

291

292

293

294

295

296

297

298

299

300

301

302

303

Where $\boldsymbol{m}$ is the mass that corresponds to the output of the first neuron from Layer 3 , $\boldsymbol{g}$ is the value of the gravity constant $\left(\mathbf{9 . 8} \frac{\mathrm{m}}{\mathrm{s}^{2}}\right)$ (The multiplication of mass times gravity $\mathrm{m}^{*} \mathrm{~g}$ yields the weight of an object); Per, the perimeter is the output of the second neuron, from Layer 3; and $\boldsymbol{T}_{\boldsymbol{k}}$ is the value of the surface tension in neuron $k$, which were associated to the surface tensions of four liquids: Ethanol (22.1), Ethylene glycol (47.7), Water (72.8), and Mercury (425.41) (Surface tension value $(\mathrm{mN} / \mathrm{m})$ at $20^{\circ} \mathrm{C}$ ) (Jasper, 1972). The four liquids shown above were used, as they are common, relatively wellknown, and present different surface tensions. Here, the main idea was the relationship that exists between the four surface tensions and the different weights of objects that can break the surface tension of the liquid. For our model, the surface tension of each liquid was similar to each level of psychosocial risk, where the lowest risk level corresponded to the surface tension of the ethanol, and the very high-risk level was equivalent to the surface tension of the mercury. In this sense, when a person has, according to the psychosocial evaluation, a high-risk level, the parameters in the new surface tension neuron will be equivalent to having traveled the surface tension of ethanol, of ethylene glycol, to finally break the surface tension of the Water. Theoretically, at this point the liquid tension will be broken and the classification of the patient under study will be high risk.

The $O_{k}$ transfer function was used, owing to its behavior. Note that:

$$
\lim _{x \rightarrow \infty}\left(1-e^{-x}\right)=1
$$

$$
\lim _{x \rightarrow 0}\left(1-e^{-x}\right)=0
$$

Thus, when the force exerted by the weight was greater than that exercised by the liquid, the surface tension was broken (See Fig. 2). When this occurs, $O_{k}$ tends to be one, and when it does not, the value of $O_{k}$ tends to be zero.

The correct outputs for the four types of risk must be as shown below: 
$\left\{\begin{array}{l}\text { Risk 1, } O=\{1,0,0,0\} \\ \text { Risk 2, } O=\{1,1,0,0\} \\ \text { Risk 3, } O=\{1,1,1,0\} \\ \text { Risk 4, } O=\{1,1,1,1\}\end{array}\right.$

304

305

306

307

308

309

310

311

312

313

314

315

316

317

318

$$
\begin{gathered}
\frac{\partial \text { errorcm }}{\partial Y_{1}^{3}}=\frac{\partial \text { errorcm }}{\partial m}=\frac{\partial \text { errorcm }}{\partial O_{k}} * \frac{\partial O_{k}}{\partial m} \\
\frac{\partial O_{k}}{\partial m}=\frac{g}{T_{k} * P e r} e^{\frac{-m * g}{T_{k} * P e r}}
\end{gathered}
$$

Risk 4 breaks through all surface tensions, while Risk 1 only breaks through the first surface tension.

$$
\text { errorcm }=\sum_{k=1}^{4} \frac{\left(O_{k}-E_{k}\right)^{2}}{2}
$$

The following steps calculated the influence of each parameter on neuron network error, through error backpropagation, throughout partial derivatives. The equation below was derived from $O_{k}$ :

The derivative of the error, regarding neural network output:

$$
\frac{\text { derrorcm }}{\partial O_{k}}=\sum_{k=1}^{4}\left(O_{k}-E_{k}\right)
$$

The derivative of the error, regarding layer 3 output:

319

$$
\frac{\text { errorcm }}{\partial Y_{2}{ }^{3}}=\frac{\text { derrorcm }}{\partial P e r}=\frac{\text { derrorcm }}{\partial O_{k}} * \frac{\partial O_{k}}{\partial P e r}
$$




$$
\begin{gathered}
\frac{\partial O_{k}}{\partial P e r}=\frac{-m * g}{T_{k} * \text { Per }^{2}} e^{\frac{-m * g}{T_{k} * P e r}} \\
\frac{\partial \text { errorcm }}{\partial Y^{3}}=\left\{\frac{\partial \text { errorcm }}{\partial Y_{1}^{3}}, \frac{\partial \text { errorcm }}{\partial Y_{2}^{3}}\right\}
\end{gathered}
$$

320

321 Derivative of error, according to layer 3 weights:

$$
\begin{gathered}
\frac{\partial \text { errorcm }}{\partial w_{k, i}{ }^{3}}=\frac{\partial \text { errorcm }}{\partial Y_{k}{ }^{3}} * \frac{\partial Y_{k}^{3}}{\partial w_{k, i}{ }^{3}} \\
\text { for } k=1 \text { to } 80, \text { with } i=1 \text { and } 2 \\
\frac{\partial Y_{k}^{3}}{\partial w_{k, i}{ }^{3}}=Y_{i}^{2}
\end{gathered}
$$

322

323 Derivative of error, according to layer 3 bias:

$$
\frac{\text { derrorcm }}{b_{k}{ }^{3}}=\frac{\partial \text { errorcm }}{\partial Y_{k}{ }^{3}} * \frac{\partial Y_{k}^{3}}{b_{k}{ }^{3}}
$$

324

325 Derivative of error, according to layer 2 output:

$$
\begin{gathered}
\frac{\text { derrorcm }}{\partial Y_{i}^{2}}=\sum_{k=1}^{2} \frac{\partial \text { errorcm }}{\partial Y_{k}^{3}} * \frac{\partial Y_{k}^{3}}{Y_{i}^{2}} \\
\text { for } i=1 \text { to } 80
\end{gathered}
$$

326

$$
\begin{gathered}
\frac{\text { derrorcm }}{\partial Y_{i}^{2}}=\sum_{k=1}^{2} \frac{\text { derrorcm }}{\partial Y_{k}^{3}} * w_{k, i}{ }^{3} \\
\text { for } i=1 \text { to } 80
\end{gathered}
$$

Derivative of error, according to layer 2 weights: 


$$
\frac{\partial \text { errorcm }}{\partial y^{2}}=\frac{\text { derrorcm }}{\partial Y^{2}} * \frac{\partial Y^{2}}{\partial y^{2}}
$$

328

$$
\begin{gathered}
\frac{\partial Y^{2}}{\partial y^{2}}=1-\left(Y^{2}\right)^{2} \\
\frac{\partial \text { errorcm }}{w_{k, i}^{2}}=\frac{\partial \text { errorcm }}{\partial Y^{2}} * \frac{\partial Y^{2}}{\partial y^{2}} * \frac{\partial y^{2}}{w_{k, i}^{2}} \\
\text { for } k, i=1 \text { to } 80
\end{gathered}
$$

329

330 Derivative of error, according to layer 2 bias:

$$
\begin{gathered}
\frac{\text { derrorcm }}{b_{k}{ }^{2}}=\frac{\partial \text { errorcm }}{\partial Y^{2}} * \frac{\partial Y^{2}}{\partial y^{2}} * \frac{\partial y^{2}}{b_{k}{ }^{2}} \\
\frac{\partial y^{2}}{b_{k}{ }^{2}}=1
\end{gathered}
$$

331

332 Derivative of error, according to layer 1 output:

$$
\frac{\partial \text { errorcm }}{\partial Y^{1}}=\frac{\partial \text { errorcm }}{\partial Y^{2}} * \frac{\partial Y^{2}}{\partial y^{2}} * \frac{\partial y^{2}}{\partial Y^{1}}
$$

333

334 Derivative of error, according to layer 1 weights:

$$
\frac{\partial y^{2}}{\partial Y^{1}}=w_{k, i}^{3} \text { for } i, k=1 \text { to } 80
$$

335

$$
\begin{gathered}
\frac{\partial \text { errorcm }}{\partial y^{1}}=\frac{\partial \text { errorcm }}{\partial Y^{2}} * \frac{\partial Y^{2}}{\partial y^{2}} * \frac{\partial y^{2}}{\partial Y^{1}} * \frac{\partial Y^{1}}{\partial y^{1}} \\
\frac{\partial Y^{1}}{\partial y^{1}}=1-\left(Y^{1}\right)^{2}
\end{gathered}
$$




$$
\frac{\partial \text { errorcm }}{\partial w_{k, i}{ }^{1}}=\frac{\partial \text { errorcm }}{\partial Y^{2}} * \frac{\partial Y^{2}}{\partial y^{2}} * \frac{\partial y^{2}}{\partial Y^{1}} * \frac{\partial Y^{1}}{\partial y^{1}} * \frac{\partial y^{1}}{\partial w_{k, i}{ }^{1}}
$$

337

$$
\frac{\partial y^{1}}{\partial w_{k, i}{ }^{1}}=E_{i} \text { for } k=1 \text { to } 80 ; i=1 \text { to } 20
$$

338

339 Derivative of error, according to layer 1 bias:

$$
\begin{gathered}
\frac{\partial \text { errorcm }}{\partial b^{1}}=\frac{\partial e r r o r c m}{\partial Y^{2}} * \frac{\partial Y^{2}}{\partial y^{2}} * \frac{\partial y^{2}}{\partial Y^{1}} * \frac{\partial Y^{1}}{\partial y^{1}} * \frac{\partial y^{1}}{\partial b^{1}} \\
\frac{\partial y^{1}}{\partial b^{1}}=1
\end{gathered}
$$

340

$$
\frac{\text { derrorcm }}{\text { dparameters }}=\left(\begin{array}{l}
\frac{\text { errorcm }}{\partial b^{1}}, \frac{\text { errorcm }}{\partial w^{1}}, \ldots \\
\frac{\partial \text { errorcm }}{\partial b^{2}}, \frac{\partial \text { errorcm }}{\partial w^{2}}, \ldots \\
\frac{\partial \text { errorcm }}{\partial b^{3}}, \frac{\partial \text { errorcm }}{\partial w^{3}}
\end{array}\right)
$$

341 The new parameters in iteration $n+1$ were calculated throughout the conjugate gradient 342 method:

$$
\operatorname{parameters}(n+1)=\operatorname{parameters}(n)+\eta(n) * d(n)
$$

343 Where,

$$
\eta(n) * d(n)
$$

344 Depends on the

$$
\frac{\text { derrorcm }}{\text { dparameters }} \text { values. }
$$

This procedure was repeated, beginning at step in equation 4 for the remaining training data, thus completing the first iteration. Later, iterations were performed repeatedly until there was an artificial neural network convergence, according with the following three stop 
349

350

351

352

353

354

355

356

357

358

359

360

361

362

363

364

365

366

367

368

369

370

tolerance was assigned for adequate neuron network learning; b) Performance, in order to measure neural network performance, the mean squared error was employed. The value to be achieved is zero, so as to avoid presenting neural output errors; c) Number of Iterations, the training was stopped if 300 iterations were reached. A high number of iterations was chosen, as ideally, it stopped with error criteria.

The code developed in Matlab V9.4 software can be consulted here: https://codeocean.com/capsule/6532855/tree/v1 (Mosquera, Castrillón Gómez \& ParraOsorio, 2019).

\section{Statistical analysis}

The data set was divided into training (80\%) and test (20\%) groups (train/test split) as published in (Vabalas et al., 2019). For the evaluation of the algorithm the following metrics were used (Rose, 2018): a) Sensitivity, which provides the probability that, given a positive observation, the neural network will classify it as positive (50); b) Specificity, which provides the probability that, given a negative observation, the neural network will classify it as negative (51); c) Accuracy, which gives the total neural network accuracy percentage (52) and, d) the ROC curve by plotting the sensitivity (true-positive rate) against the falsepositive rate ( 1 - specificity) at various threshold settings. Different authors in other studies as have been used the sensitivity, specificity, and, AUC, for the performance statistics within the independent dataset (Le, Ho \& Ou, 2017; Do, Le \& Le, 2020; Le et al., 2020).

$$
\text { Sensitivity }=\frac{T P}{T P+F N}
$$

$$
\text { Specificity }=\frac{T N}{T N+F P}
$$

371

372

373

374

375

376

377

378

379

$$
\text { Accuracy }=\frac{T P+T N}{T P+T N+F P+F N}
$$

Where TP, TN, FP and FN denote the number of true positives, true negatives, false positives and false negatives, respectively. In order to analyze the stability of the system in the results obtained, a variance analysis, using equation (53) was performed, to establish whether there were significant differences in the results. In this analysis, representing the response to the variables, $T_{i}$, was the effect caused by $n$th treatment, and $\varepsilon i$, the nth experimental error. The information collected must comply with independence and normality requirements. The variance analysis was performed under a confidence interval of $99.5 \%$ (Rodriguez, 2007):

$$
Y_{i}=\mu+T_{i}+\varepsilon_{i}
$$


381

382

383

384

385

386

387

388

389

390

391

392

393

394

395

396

397

398

399

400

401

402

403

404

405

406

407

408

409

410

411

412

413

414

415

416

417

418

419

420

421

422

423

The efficiency of the PST-NN approach was compared with previous published techniques (Mosquera, Parra-Osorio \& Castrillón, 2016; Mosquera, Castrillón \& Parra, 2018a,b; Mosquera, Castrillón \& Parra-Osorio, 2019), which were applied over the original data included in the present work. Accuracy was the metric used to make the comparison between PST-NN and Decision Tree J48, Naïve Bayes, Artificial Neural Network, Support Vector Machine Linear, Hill Climbing-Support Vector Machine, KNearest Neighbors-Support Vector Machine, Robust Linear Regression, and Logistic Regression Models.

\section{Results}

\section{Adjustment of the PST-NN approach}

The 20 input variables (psychosocial, physiological, and musculoskeletal symptoms) belonging to the 5443 subjects were used to train and test the Physical Surface Tension Neural Net (PST-NN), according with the level of risk in which the person may be characterized (low, medium, high, and very high risk).

Figure 3 shows the mean squared error that was obtained during the training and testing process of the PST-NN approach, as a function of the iterations number that was used in the adjustment of the neural network parameters. The trend of the blue line, corresponding to the training group, showed how the mean squared error rapidly decreases around the first 100 iterations, reaching a plateau for higher values of the iterations. This plateau indicated that the neural net model has reached the parameters optimization and therefore, any additional increment in the number of iterations not significatively improve the parameters adjustment. Concretely, in in this study and for the next results, 108 iterations were considered in the adjustment of the PST-NN parameters. The curve of the mean squared error corresponding to the testing group (red line) showed a similar behavior to the training group. Indeed, the following results were reported only for the test set.

In relation with the layer that represents the surface tension model in the PST-NN approach (Fig.1), Figure 4 showed the results of the perimeter and mass outputs for each subject in the test group, according with the risk level. The outputs were plotted in a XY graph, where the mass output corresponds to the $X$ axes and the perimeter to the $Y$ axes. As result, it was possible to see that the points were grouped in specific areas as a function of the risks level. In this sense, the types of risk may additionally be interpreted in physical form. Indeed, the highest risk in the graph corresponded to the red crosses, which present mass values which were relatively larger than the rest, along with relatively smaller perimeters, which cause the surface tension of the four liquids to break. The lowest risk (represented in blue with asterisks) had relatively high perimeters and relatively low masses, which cause them to remain on the surface of certain liquids.

The square root of the mass/perimeter relationship was represented in Fig.5. This transformation of the relationship between mass and perimeter was applied only for improved visualization of the separations between the risk levels. The figure showed that the lowest value of the square root of the mass/perimeter relationship corresponded to the lowest risk level and the highest value to the highest risk level. 
424

425

426

427

428

429

430

431

432

433

434

435

436

437

438

439

440

441

442

443

444

445

446

447

448

449

450

451

452

453

454

455

456

457

458

459

460

461

462

463

464

465

\section{Classification performance of the PST-NN approach}

The specific confusion matrix for the test set (Table 4) showed the performance of the PST-NN algorithm, as a function of the TP, TN, FP and FN. The number of subjects in each target risk group was 116, 117, 347, and 521 for risk levels 1, 2, 3, and 4, respectively. The number of subjects classified by the algorithm in each risk group was 109 (Risk Level 1), 113 (Risk Level 2), 339 (Risk Level 3), and 540 (Risk Level 4).

Table 5 included the values of sensitivity, specificity, accuracy and AUC for each of the risk levels in the test set. The highest sensitivity value was $97.5 \%$ (Risk level 4 ) and the lowest sensitivity value was $77.8 \%$ (Risk level 2), indicating that Risk Level 2 was the most difficult type of risk to classify. On the contrary, the best specificity value was obtained in Risk level 1 (98.2\%) and the lowest was in Risk level 3 (96.0\%). In relation to the accuracy, Risk Level 2 had the lowest value, indicating that the surface tension neural network would correctly classify an individual, with a probability of the $82.7 \%$, to belong or not to this risk level (it includes true positive and true negative cases). The risk levels with the greatest accuracy values were Risk level 1 followed by Risk level 4, with values of $98.85 \%$ and 97.37, respectively. Complementary, Figure 6 showed the receiver operating characteristic curves (ROC curve) for each risk level for the test set. Risk level 4 had the best classification with AUC value of 0.984 (Table 5), while Risk level 2 was the one that presents the most confusion on classification ( $A \cup C=0.883$ ).

Finally, the performance of the PST-NN approach was compared in terms of accuracy against the results of linear, probabilistic, and logistic models, previously published (see Table 6). The proposed PST-NN method had the best accuracy value ( $97.31 \%)$, followed by Support Vector Machines (92.86\%), Hill-Climbing-Support Vector Machines (92.86\%), and Artificial Neural Networks (92.83\%). The lowest accuracy values were obtained with the Robust Linear Regression (53.47\%), and Logistic Regression (53.65\%) techniques. The statistical stability analysis, based on the ANOVA method, showed statistically significant differences between PST-NN and the other techniques, in relation to the accuracy values, with $p$-value $<0.05$.

\section{Discussion}

In this study, the Physical Surface Tension-Neural Net (PST-NN) approach was developed and applied to model and predict psychosocial risk levels among Colombian state-school teachers. The fundamental point of the structure of this model was the improvement of the neural model by the adaptation of a layer that includes concepts related to the theory of physical surface tension. Indeed, the psychosocial risk level was associated with the probability that a "surface" can be broken as a function of the psychosocial, physiological, and musculoskeletal factors impact. For each risk level, a different value of the physical surface tension was set in analogy with the surface tensions of four common liquids (Ethanol, Ethylene glycol, Water, and Mercury). This attempts to benefit from the characteristics of neural networks and increase precision via innovation (theory of physical surface tension), in the form of neural network modification. It is expected that this 
466 combination enables the elimination of linear model deficiencies and the development of

467

468

469

470

471

472

473

474

475

476

477

478

479

480

481

482

483

484

485

486

487

488

489

490

491

492

493

494

495

496

497

498

499

500

501

502

503

504

505

506

507

508

509

510 an approach to the real world, with fewer shortcomings.

This technique presented an important advantage, due it allowed the dimensionality in the input variables to be reduced. In this study, the 20 input variables in the first layer of the neural network were reduced to 2 variables (mass and perimeter) in the surface tension layer, in order to facilitate the classification process. In this layer, the surface tension equation intervened to replace the network sigmoid function, which reduced data variability and dimensionality, improving the response in the classification and resulting error. The results reported in Fig. 4 and 5 supported this behavior, so it was possible to see a clear grouping of the subjects according to the risk level group, as a function of the mass and perimeter outputs. This was according to the surface tension theory by which a low mass and high perimeter reduce the probability of breaking the surface, and on the contrary, a high mass with a low perimeter increases that probability.

The neural network models possess high flexibility and fewer parameters compared with parametric models (Darvishi et al., 2017). Results in Fig. 3 showed that the neural model iteration process quickly catches up to the number of iterations necessary to establish the model and provide objective, precise results. However, in supervised machine learning, overfitting could be present, indicating that model does not generalize well from observed data to unseen data (Ying, 2019). Because of that, the model performs better on training set that in testing set. In order to reduce the effect of overfitting during the adjustment process of the PST-NN parameters, the train/test split methodology (Vabalas et al., 2019), besides to the control in the number of iterations during the neural network training, and the normalization and reduction in dimensionality of the input data, were used. (Ying, 2019). However, the number of subjects in each risk level group was not uniformly distributed, being the Risk level 4 the group with more subjects, and Risk level 1 and 2 the groups with less subjects. This situation could generate that the PST-NN model tends to memorize in more detail the data belonging to Risk level 4, and in less detail the data of Risk level 1 and 2.

The application of the PST-NN approach to the data belonging to Colombian stateschool teachers, showed an average accuracy value of $97.31 \%$ in the psychosocial risk classification, including all the risk level groups and all the subjects in the database. The confusion matrix results (Table 4) and ROC curve (Fig. 6) demonstrated that the PST-NN model was highly efficient, in terms of psychosocial risk classification, as compared to other experiments and models (Larrabee et al., 2003; Baradaran, Ghadami \& Malihi, 2008; Aliabadi, 2015; Farhadian, Aliabadi \& Darvishi, 2015; Yigit \& Shourabizadeh, 2017; Jebelli, Khalili \& Lee, 2019). The level of precision and low error percentage of PST-NN approach demonstrated the ease adaptation of the mathematical structure to the input variables, generating a model that can be used to perform preventive interventions in occupational health by way of prediction, based on psychosocial, physiological, and musculoskeletal factors.

Psychosocial, physiological, and musculoskeletal factors fundamentally involve nonlinear relationships. While neural networks are linear models that provide adequate approaches for the classification problem, the introduction of a physical concept to the neural model, such as the physical surface tension theory, adapted better to the type of data present in organizational and psychosocial climate evaluations. As such, the PST-

Peer) Comput. Sci. reviewing PDF | (CS-2020:06:50165:2:0:NEW 20 Feb 2021) 
511 NN model, by way of the transformation and neural suitability procedure, may discover 512 improved solutions. Alternatively, other authors (Tzeng, Hsieh \& Lin, 2004; Hong et al., 513 2005; Azadeh et al., 2015; Jebelli, Khalili \& Lee, 2019) have avoided the non-linear 514 relationships transforming the data in four linear variables: a positive relationship, 515 negative relationship, no relationship, and non-linear relationship, in studies to analyze 516 the performance and personnel turnover data. However, the results showed values of 517 classification and prediction that could be improved.

The performance of the PST-NN approach, for psychosocial risk level prediction, showed better average accuracy value $(97.31 \%)$ than the results of support vector machine linear models, neural networks, probabilistic models, linear and logistic regression models, and decision tree models, previously published (Table 6). Particularly, the ANN model, corresponding to a perceptron neural network without the modification proposed in this study, only reached an average accuracy value of $92.83 \%$, suggesting that the modification introduced by the PST-NN approach could significatively improve the classification performance. The use of regression techniques showed that the misclassification probability was high, with accuracy values of $53.47 \%$ and $53.65 \%$ for the Robust Linear Regression and Logistic Regression, respectively. This suggest that linear models are not well fitted to the type of data that were used in the present study.

The results of previous experiments support the opinion that the strategy of combining different methods (physical surface tension theory and artificial neural networks) may improve predictive performance. Similar strategies have been applied previously to work safety and health classification problems, for work stress, psychosocial factor, and mental stress factor prediction (Jackofsky, Ferris \& Breckenridge, 1986; Somers, 1999; Kursad Zorlu, 2012; Sriramprakash, Prasanna \& Murthy, 2017; Subhani et al., 2017; Xia, Malik \& Subhani, 2018; Lotfan et al., 2019).

In all industries and organizations, analysis of the psychosocial risk level is very important. Studies have shown the direct relationship between psychosocial risks and the gross domestic products of nations (Dollard et al., 2007). The implementation of artificial intelligence techniques can contribute to the development of this field of research, which could be called psychosocial analytics. It's vital the development of these types of tools in global occupational and public health. Colombia's leadership in Ibero-America in the development of tools which contribute to the occupational health and safety field is highlighted by this kind of work.

As a limitation, is important to point that the performance of the prediction model depends on both the quality and quantity of the dataset, as well as the optimal structure design. Indeed, and for the PST-NN model developed in this study, the performance will be affected by the psychosocial factor management, which depends, among other things, of the teacher population and if the data is taken by region, or similar geographical areas or annexes. When this is not the case, model function is affected, and high error rates and low precision levels are generated, as is significant statistical data dispersion. Thus, to predict performance and implement prevention programs for workers, data should be grouped from culturally, politically, socially, and economically similar regions. 
555

556

557

558

559

560

561

562

563

564

565

566

567

568

569

570

571

572

573

574

575

576

577

578

579

580

581

582

583

584

585

586

587

588

589

A novel approach, the Physical Surface Tension-Neural Net (PST-NN), was proposed in this study to classify psychosocial risk levels among Colombian state-school teachers. Psychosocial, physiological, and musculoskeletal input variables were used to train and test the PST-NN, as a function of four risk level groups (low, medium, high, and very high risk).

The proposed method obtained better classification results than models such as Decision Tree, Naïve Bayes, Artificial Neural Networks, Support Vector Machines, HillClimbing-Support Vector Machines, k-Nearest Neighbor-Support Vector Machine, Robust Linear Regression, and Logistic Regression. Indeed, the PST-NN had an average accuracy value of $97.31 \%$, including all the risk level groups and all the subjects in the database.

The results obtained in the prediction of the model demonstrated that the proposed PST-NN approach is applicable for the identification of the psychosocial risk level among Colombian state-school teachers, with high levels of accuracy, and it may contribute as a tool in the generation of guidelines in public health plans, defined by the government.

\section{Acknowledgements}

This work was financial supported by the "Convocatoria Nacional para el Apoyo al Desarrollo de Tesis de Posgrado o de Trabajos Finales de Especialidades en el área de la Salud de la Universidad Nacional de Colombia 2017-2018", Resolution 21, december 2017, Vicerrectoria de Investigaciones, proposal number Hermes 40976, and Quipu code 201010016754. Also, it was financial supported by the "Universidad de San Buenaventura, Cali, Facultad de Ingeniería, NTTG and LEA research groups".

\section{References}

Adamson AW, Gast AP. 1967a. Arthur W. Adamson, Alice P. Gast - Physical chemistry of surfaces. New York: Interscience publishers 150.

Adamson AW, Gast AP. 1967b. Physical chemistry of surfaces. New York, N.Y, USA: Interscience.

Aliabadi M. 2015. Prediction of hearing loss among the noise-exposed workers in a steel factory using artificial intelligence approach. Int Arch Occup Environ Health:9.

Almeida HFD, Carvalho PJ, Kurnia KA, Lopes-da-Silva JA, Coutinho JAP, Freire MG. 2016. Surface tensions of ionic liquids: Non-regular trend along the number of cyano groups. Fluid Phase Equilibria 409:458-465. DOI: 10.1016/j.fluid.2015.10.044. 
590 Andayani U, Nababan EB, Siregar B, Muchtar MA, Nasution TH, Siregar I. 2017. Optimization

591

592

593

594

595

596

597

598

599

600

601

602

603

604

605

606

607

608

609

610

611

612

613

614

615 backpropagation algorithm based on Nguyen-Widrom adaptive weight and adaptive learning rate. In: 2017 4th International Conference on Industrial Engineering and Applications (ICIEA). Nagoya, Japan: IEEE, 363-367. DOI: 10.1109/IEA.2017.7939239.

Azadeh A, Alizadeh Bonab N, Salehi V, Zarrin M. 2015. A unique algorithm for the assessment and improvement of job satisfaction by resilience engineering: Hazardous labs. International Journal of Industrial Ergonomics 49:68-77. DOI: 10.1016/j.ergon.2015.06.002.

Baradaran V, Ghadami S, Malihi SE. 2008. A Multi Objective approach for selecting solutions to improve job satisfaction an empirical case analysis. In: 2008 IEEE International Conference on Industrial Engineering and Engineering Management. Singapore, Singapore: IEEE, 1945-1948. DOI: 10.1109/IEEM.2008.4738211.

Bitalino. 2017. BITalino. Italy.

Bruhn A, Frick K. 2011. Why it was so difficult to develop new methods to inspect work organization and psychosocial risks in Sweden. Safety Science 49:575-581. DOI: 10.1016/j.ssci.2010.07.011.

Collie RJ, Shapka JD, Perry NE. 2012. School climate and social-emotional learning: Predicting teacher stress, job satisfaction, and teaching efficacy. Journal of Educational Psychology 104:1189-1204. DOI: 10.1037/a0029356.

Darvishi E, Khotanlou H, Khoubi J, Giahi O, Mahdavi N. 2017. Prediction Effects of Personal, Psychosocial, and Occupational Risk Factors on Low Back Pain Severity Using Artificial Neural Networks Approach in Industrial Workers. Journal of Manipulative and Physiological Therapeutics 40:486-493. DOI: 10.1016/j.jmpt.2017.03.012.

Dediu V, Leka S, Jain A. 2018. Job demands, job resources and innovative work behaviour: a European Union study. European Journal of Work and Organizational Psychology 27:310-323. DOI: 10.1080/1359432X.2018.1444604.

Peer] Comput. Sci. reviewing PDF | (CS-2020:06:50165:2:0:NEW 20 Feb 2021) 
616 Do DT, Le TQT, Le NQK. 2020. Using deep neural networks and biological subwords to detect

617 protein S-sulfenylation sites. Briefings in Bioinformatics:bbaa128. DOI:

$618 \quad 10.1093 /$ bib/bbaa128.

619 Dollard M, Skinner N, Tuckey MR, Bailey T. 2007. National surveillance of psychosocial risk 620 factors in the workplace: An international overview. Work \& Stress 21:1-29. DOI:

$621 \quad 10.1080 / 02678370701254082$.

622 El-Batawi MA. 1988. Psychosocial health problems of workers in developing countries. In:

623 Psychosocial factors at work and their relationship with health. 1. Bélgica: World Health

624 Organization, 15-20.

625 Farhadian M, Aliabadi M, Darvishi E. 2015. Empirical estimation of the grades of hearing

626 impairment among industrial workers based on new artificial neural networks and

627

628 classical regression methods. Indian Journal of Occupational and Environmental Medicine 19:84-89. DOI: 10.4103/0019-5278.165337.

629

Fowkes FM. 1962. Determination of interfacial tensions, contact angles, and dispersion forces in 630 surfaces by assuming additivity of intermolecular interactions in surfaces. 66:382-382.

631 DOI: $10.1021 / \mathrm{j} 100808 \mathrm{a} 524$.

632

633

Harrington P de B. 1993. Sigmoid transfer functions in backpropagation neural networks. Analytical Chemistry 65:2167-2168. DOI: 10.1021/ac00063a042.

635

Hong W-C, Pai P-F, Huang Y-Y, Yang S-L. 2005. Application of Support Vector Machines in Predicting Employee Turnover Based on Job Performance. In: Wang L, Chen K, Ong YS eds. Advances in Natural Computation. Lecture Notes in Computer Science. Berlin, Heidelberg: Springer Berlin Heidelberg, 668-674. DOI: 10.1007/11539087_85. Between Job Performance and Turnover. Journal of Management 12:105-111. DOI: 10.1177/014920638601200109. 
641 Jasper JJ. 1972. The Surface Tension of Pure Liquid Compounds. 1(4):841-1010. DOI:

$642 \quad 10.1063 / 1.3253106$.

643 Jebelli H, Khalili MM, Lee S. 2019. Mobile EEG-Based Workers' Stress Recognition by Applying

644 Deep Neural Network. In: Mutis I, Hartmann T eds. Advances in Informatics and

645 Computing in Civil and Construction Engineering. Cham: Springer International

646 Publishing, 173-180. DOI: 10.1007/978-3-030-00220-6_21.

647 Karasek RA. 1979. Job Demands, Job Decision Latitude, and Mental Strain: Implications for Job

648 Redesign. Administrative Science Quarterly 24:285. DOI: 10.2307/2392498.

649 Kinman G. 2001. Pressure Points: A review of research on stressors and strains in UK 650 academics. Educational Psychology 21:473-492. DOI: 10.1080/01443410120090849.

651 Kursad Zorlu. 2012. The perception of self-esteem and self-efficacy as transforming factors in

652 the sources of role stress and job satisfaction relationship of employees: A trial of a

653 staged model based on the artificial neural network method. AFRICAN JOURNAL OF

654 BUSINESS MANAGEMENT 6. DOI: 10.5897/AJBM11.2345.

655 Larrabee JH, Janney MA, Ostrow CL, Withrow ML, Hobbs, GR, Burant C. 2003. Predicting

656 Registered Nurse Job Satisfaction and Intent to Leave: JONA: The Journal of Nursing

657 Administration 33:271-283. DOI: 10.1097/00005110-200305000-00003.

658 Law K-Y, Zhao H, Strojnisìtva. inzl̀enirka. 2016. Surface wetting : characterization, contact

659 angle, and fundamentals. Springer.

660 Le NQK, Do DT, Chiu F-Y, Yapp EKY, Yeh H-Y, Chen C-Y. 2020. XGBoost Improves

661 Classification of MGMT Promoter Methylation Status in IDH1 Wildtype Glioblastoma.

662 Journal of Personalized Medicine 10:128. DOI: 10.3390/jpm10030128.

663 Le N-Q-K, Ho Q-T, Ou Y-Y. 2017. Incorporating deep learning with convolutional neural

664 networks and position specific scoring matrices for identifying electron transport proteins.

665 Journal of Computational Chemistry 38:2000-2006. DOI: 10.1002/jcc.24842.

666 Lida T, Guthrie RIL. 1993. The Physical Properties of Liquid Metals. 
667 Lippel K, Quinlan M. 2011. Regulation of psychosocial risk factors at work: An international 668 overview. Safety Science 49:543-546. DOI: 10.1016/j.ssci.2010.09.015.

669 Lotfan S, Shahyad S, Khosrowabadi R, Mohammadi A, Hatef B. 2019. Support vector machine 670 classification of brain states exposed to social stress test using EEG-based brain 671 network measures. Biocybernetics and Biomedical Engineering 39:199-213. DOI: $672 \quad$ 10.1016/j.bbe.2018.10.008.

673 Macleod DB. 1923. On a relation between surface tension and density. Transactions of the $674 \quad$ Faraday Society 19:38. DOI: 10.1039/tf9231900038.

675 Mosquera R, Castrillón Gómez OD, Parra-Osorio L. 2018. Psychosocial Risk Level Colombian 676 Teachers School Repository 2016-2017. DOI: 10.5281/zenodo.1298610.

677 Mosquera R, Castrillón Gómez OD, Parra-Osorio L. 2019. Algorithm based on Physical Surface 678 Tension for the Prediction of Psychosocial-risk Level in Public School Teachers. [Source 679 Code]. Doi.org/10.24433/CO.4268666.v1.1. New York, NY 10036: Code Ocean.

680

681

682

683

684

685

686

687

688

689

690

691

692

Mosquera R, Castrillón OD, Parra L. 2018a. Predicción de Riesgos Psicosociales en Docentes de Colegios Públicos Colombianos utilizando Técnicas de Inteligencia Artificial. Información tecnológica 29:267-280. DOI: 10.4067/S0718-07642018000400267.

Mosquera R, Castrillón OD, Parra L. 2018b. Máquinas de Soporte Vectorial, Clasificador Naïve Bayes y Algoritmos Genéticos para la Predicción de Riesgos Psicosociales en Docentes de Colegios Públicos Colombianos. Información tecnológica 29:153-162. DOI: 10.4067/S0718-07642018000600153.

Mosquera R, Castrillón OD, Parra-Osorio L. 2019. Aplicación del modelo hibrido k-nearest neighbors- Support Vector Machine para la predicción del riesgo psicosocial en docentes de colegios públicos colombianos. Proceedings of the 17th Latin American and Caribbean Conference for Engineering and Technology, 1:5.

Mosquera R, Parra-Osorio L, Castrillón OD. 2016. Metodología para la Predicción del Grado de Riesgo Psicosocial en Docentes de Colegios Colombianos utilizando Técnicas de 
693

694

695

696

697

698

699

700

701

702

703

704

705

706

707

708

709

710

711

712

713

714

715

716

717 Sriramprakash S, Prasanna VD, Murthy OVR. 2017. Stress Detection in Working People.

718

Minería de Datos. Información tecnológica 27:259-272. DOI: 10.4067/S071807642016000600026.

Pavelka A, Prochazka A. 2004. Algorithms for initialization of neural network weights. In Proceedings of the 12th Annual Conference, MATLAB:453-459.

Robnik-S` M, Kononenko I. 2003. Theoretical and Empirical Analysis of ReliefF and RReliefF. Machine Learning 53:23-69. DOI: 10.1023/A:1025667309714.

Rodriguez L. 2007. Probabilidad y estadística básica para ingenieros. Ecuador: Escuela Superior Politécnica del Litorallnstituto de Ciencias Matemáticas.

Rose S. 2018. Machine Learning for Prediction in Electronic Health Data. JAMA Network Open 1:e181404. DOI: 10.1001/jamanetworkopen.2018.1404.

Saidatul A, Paulraj MP, Yaacob S, Yusnita MA. 2011. Analysis of EEG signals during relaxation and mental stress condition using AR modeling techniques. In: 2011 IEEE International Conference on Control System, Computing and Engineering. Penang, Malaysia: IEEE, 477-481. DOI: 10.1109/ICCSCE.2011.6190573.

Sali R, Roohafza H, Sadeghi M, Andalib E, Shavandi H, Sarrafzadegan N. 2013. Validation of the Revised Stressful Life Event Questionnaire Using a Hybrid Model of Genetic Algorithm and Artificial Neural Networks. Computational and Mathematical Methods in Medicine:8.

Sauter SL, Murphy LR. 1984. Factores psicosociales y de organización. Enciclopedia de salud y seguridad en el trabajo:34.2-34.75.

Siegrist J. 1996. Adverse Health Effects of High-Effort/Low-Reward Conditions. Journal of Occupational Health Psychology 1:27-41.

Somers MJ. 1999. Application of Two Neural Network Paradigms to the Study of Voluntary Employee Turnover. :9.

Procedia Computer Science 115:359-366. DOI: 10.1016/j.procs.2017.09.090.

Peer] Comput. Sci. reviewing PDF | (CS-2020:06:50165:2:0:NEW 20 Feb 2021) 
719 Subhani AR, Mumtaz W, Saad MNBM, Kamel N, Malik AS. 2017. Machine Learning Framework 720 for the Detection of Mental Stress at Multiple Levels. IEEE Access 5:13545-13556. DOI: $721 \quad$ 10.1109/ACCESS.2017.2723622.

722 Tyson WR, Miller WA. 1977. Surface free energies of solid metals: Estimation from liquid 723 surface tension measurements. Surface Science 62:267-276. DOI: 10.1016/0039$724 \quad 6028(77) 90442-3$.

725 Tzeng H-M, Hsieh J-G, Lin Y-L. 2004. Predicting Nurses' Intention to Quit With a Support Vector $726 \quad$ Machine. :11.

727 Vabalas A, Gowen E, Poliakoff E, Casson AJ. 2019. Machine learning algorithm validation with 728 a limited sample size. PLOS ONE 14:e0224365. DOI: 10.1371/journal.pone.0224365.

729 Weissbrodt R, Giauque D. 2017. Labour inspections and the prevention of psychosocial risks at 730 work: A realist synthesis. Safety Science 100:110-124. DOI: 10.1016/j.ssci.2017.02.012.

731 Wenhui Liao, Weihong Zhang, Zhiwei Zhu, Qiang Ji. 2005. A Real-Time Human Stress

732 Monitoring System Using Dynamic Bayesian Network. In: 2005 IEEE Computer Society Conference on Computer Vision and Pattern Recognition (CVPR'05) - Workshops. San

734 Diego, CA, USA: IEEE, 70-70. DOI: 10.1109/CVPR.2005.394.

Xia L, Malik AS, Subhani AR. 2018. A physiological signal-based method for early mental-stress

736 detection. Biomedical Signal Processing and Control 46:18-32. DOI:

737 10.1016/j.bspc.2018.06.004.

Yigit IO, Shourabizadeh H. 2017. An approach for predicting employee churn by using data mining. In: 2017 International Artificial Intelligence and Data Processing Symposium (IDAP). Malatya: IEEE, 1-4. DOI: 10.1109/IDAP.2017.8090324.

742 Ying X. 2019. An Overview of Overfitting and its Solutions. Journal of Physics: Conference 743 Series 1168:022022. DOI: 10.1088/1742-6596/1168/2/022022. 


\section{Table $\mathbf{1}$ (on next page)}

Variables for intralaboral psychosocial risk factors. Adapted from: (Villalobos et al., 2010) 
1

2

Table 1. Variables for intralaboral psychosocial risk factors. Adapted from: (Villalobos et al., 2010)

\section{Psychosocial risk variables}

Factor Stressor Description

\begin{tabular}{|c|c|c|}
\hline $\begin{array}{l}\text { Leadership } \\
\text { and social } \\
\text { relations at } \\
\text { work }(L)\end{array}$ & $\begin{array}{c}\text { Leadership } \\
\text { characteristics }\left(L_{1}\right)\end{array}$ & $\begin{array}{l}\text { tributes of immediate superiors' management, as related to task } \\
\text { anning and assignment, attainment of results, conflict resolution, } \\
\text { articipation, motivation, support, interaction, and communication with } \\
\text { nployees. } \\
\text { formation that a worker receives regarding the way in which they do } \\
\text { eir job. This information allows the identification of strengths and } \\
\text { eaknesses, as well as action for performance maintenance or } \\
\text { iprovement. }\end{array}$ \\
\hline $\begin{array}{l}\text { Control } \\
\text { over work } \\
\quad(C)\end{array}$ & $\begin{array}{l}\text { staff training }\left(C_{2}\right) \\
\text { Skills and } \\
\text { knowledge } \\
\text { opportunities for } \\
\text { its use and } \\
\text { development }\left(C_{3}\right)\end{array}$ & $\begin{array}{l}\text { Definition and communication of the role that the worker is expected } \\
\text { to play within the organization, specifically as relates to work } \\
\text { objectives, functions, results, degree of autonomy, and the impact of } \\
\text { said role within the company. } \\
\text { Induction activities, training, and instruction provided by the } \\
\text { organization, so as to develop and strengthen worker knowledge and } \\
\text { abilities. } \\
\text { The possibility that a job provides an individual to apply, learn, and } \\
\text { develop their abilities and knowledge. }\end{array}$ \\
\hline $\begin{array}{l}\text { Work } \\
\text { Demands } \\
(D)\end{array}$ & $\begin{array}{c}\text { Quantitative } \\
\text { demands }\left(D_{3}\right) \\
\text { Influence of work } \\
\text { on the non-work }\end{array}$ & $\begin{array}{l}\text { Physical (noise, lighting, temperature, ventilation), chemical, or } \\
\text { biological (viruses, bacteria, fungi, or animals) conditions, workstation } \\
\text { design, cleanliness (order and sanitation), physical loads, and } \\
\text { industrial security. } \\
\text { Emotional demands } \\
\text { Require worker ability to: } \\
\text { a) Understand the situations and feelings of others, and b) exercise } \\
\text { self-control over their own emotions or feelings, in order to avoid } \\
\text { affecting work performance. } \\
\text { Demands relative to the amount of work to be performed and the time } \\
\text { available to do so. } \\
\text { Work demands on individuals' time and effort which impact their } \\
\text { after-work activities, personal, or family life. } \\
\text { These refer to the cognitive processing demands required for a task, } \\
\text { and which involve superior mental attention, memory, or information } \\
\text { analysis processes to generate a response. } \\
\text { The mental load is determined by the information characteristics } \\
\text { (quantity, complexity, and detail), as well as the time available to } \\
\text { process said load. } \\
\text { Work time demands made on an individual, in terms of duration and } \\
\text { work hours, including times for pauses or periodic breaks. }\end{array}$ \\
\hline$(R)$ & ork rewaras $\left(R_{1}\right)$ & $\begin{array}{l}\text { muneration granted to the worker to compensate their effort at } \\
\text { rk. This remuneration includes recognition, payment, and access to } \\
\text { Ilness services and possibilities for growth. }\end{array}$ \\
\hline
\end{tabular}




\section{Table 2 (on next page)}

Physiological variables 
Table 2. Physiological variables

Physiological variables

\begin{tabular}{ll}
\hline Heart rate $\left(P_{1}\right)$ & $\begin{array}{l}\text { Heart rate is the speed of the heartbeat measured by the number of contractions } \\
\text { (beats) of the heart per minute }(\mathrm{bpm}) \text {. }\end{array}$ \\
\hline Electrodermal & $\begin{array}{l}\text { Property of the human body that causes continuous variation in the electrical } \\
\text { characteristics of the skin. Skin conductance can be a measure of emotional and } \\
\text { activity }\left(P_{2}\right)\end{array}$ \\
$\begin{array}{l}\text { sympathetic responses. } \\
\left(P_{3}\right)\end{array}$ & $\begin{array}{l}\text { Is an electrodiagnostic medicine technique for evaluating and recording the } \\
\text { electrical activity produced by skeletal muscles. }\end{array}$ \\
\hline
\end{tabular}

2

3 


\section{Table 3 (on next page)}

Musculoskeletal symptoms 
Table 3. Musculoskeletal symptoms

\begin{tabular}{|c|c|}
\hline \multicolumn{2}{|c|}{ Physiological variables (Related to work absenteeism and psychosocial factors) } \\
\hline Symptoms & \\
\hline $\begin{array}{l}\text { Headache } \&\left(M_{1}\right) \\
\text { Cervical pain }\end{array}$ & $\begin{array}{l}\text { A headache in general is a sign of stress or emotional distress, and can } \\
\text { be associate to migraine or high blood pressure, anxiety or depression. } \\
\text { Some patients experience headache for } 2 \text { hours or less. (Headache } \\
\text { Classification Committee of the International Headache Society (IHS), } \\
\text { 2013). }\end{array}$ \\
\hline Migraine $\left(M_{2}\right)$ & $\begin{array}{l}\text { Migraines can be associate to by a severe headache that often appears } \\
\text { on one side of the head. They tend to affect people aged } 15 \text { to } 55 \text { years. } \\
\text { Symptoms include hyperactivity, hypoactivity, depression, fatigue and } \\
\text { neck stiffness and/or severe pain (Headache Classification Committee of } \\
\text { the International Headache Society (IHS), 2013). }\end{array}$ \\
\hline Shoulder pain $\left(M_{3}\right)$ & $\begin{array}{l}\text { The pain is elicited or aggravated by movement. Pain and stiffness usually } \\
\text { restrict the use of the Superior limbs and thereby limit daily activities during } \\
\text { work (van der Heijden, 1999). }\end{array}$ \\
\hline Arm pain $\left(M_{4}\right)$ & $\begin{array}{l}\text { Arm pain is caused by repetitive movements at work, usually the } \\
\text { symptoms are described as pain, discomfort, or stiffness that occurs } \\
\text { anywhere from your shoulders to your fingers. }\end{array}$ \\
\hline Back pain $\left(M_{5}\right)$ & $\begin{array}{l}\text { Back pain at work usually can affect people of any age, heavy lifting, } \\
\text { repetitive movements and sitting at a desk all day can produce a injury. }\end{array}$ \\
\hline
\end{tabular}

2 


\section{Table 4 (on next page)}

The Confusion matrix for Physical Surface Tension-Neural Net model for the prediction of psychosocial risk level. For test set (20\%) 
1

2

3

4

5

6

7

8

9

10

11

12

13

14

15

16

17

18

19

20

21

22

23

24
Table 4. The Confusion matrix for Physical Surface Tension-Neural Net model for the prediction of psychosocial risk level. For test set (20\%).

\begin{tabular}{|c|c|c|c|c|c|c|}
\hline & & Conft & Ision $\mathrm{Ma}$ & trix Tes & & \\
\hline & & $\begin{array}{c}\text { Risk } \\
1\end{array}$ & $\begin{array}{c}\text { Risk } \\
2\end{array}$ & $\begin{array}{c}\text { Risk } \\
\mathbf{3}\end{array}$ & Risk 4 & \\
\hline & $\begin{array}{c}\text { Risk } \\
1\end{array}$ & $\begin{array}{c}107 \\
9.7 \%\end{array}$ & $\begin{array}{c}1 \\
0.1 \%\end{array}$ & $\begin{array}{c}1 \\
0.1 \%\end{array}$ & $\begin{array}{c}0 \\
0 \%\end{array}$ & $\begin{array}{c}98.2 \% \\
1.8 \%\end{array}$ \\
\hline & $\begin{array}{c}\text { Risk } \\
2\end{array}$ & $\begin{array}{c}3 \\
0.3 \%\end{array}$ & $\begin{array}{c}\mathbf{9 1} \\
8.3 \%\end{array}$ & $\begin{array}{c}19 \\
1.7 \%\end{array}$ & $\begin{array}{c}0 \\
0.0 \%\end{array}$ & $\begin{array}{l}80.5 \% \\
19.5 \%\end{array}$ \\
\hline $\begin{array}{l}\text { Output } \\
\text { Class }\end{array}$ & $\begin{array}{c}\text { Risk } \\
3 \\
\end{array}$ & $\begin{array}{c}4 \\
0.4 \% \\
\end{array}$ & $\begin{array}{c}13 \\
1.2 \% \\
\end{array}$ & $\begin{array}{c}309 \\
28.1 \% \\
\end{array}$ & $\begin{array}{c}13 \\
1.2 \% \\
\end{array}$ & $\begin{array}{c}91.2 \% \\
8.8 \%\end{array}$ \\
\hline & $\begin{array}{c}\text { Risk } \\
4\end{array}$ & $\begin{array}{c}2 \\
0.2 \%\end{array}$ & $\begin{array}{c}12 \\
1.1 \%\end{array}$ & $\begin{array}{c}18 \\
1.6 \%\end{array}$ & $\begin{array}{c}\mathbf{5 0 8} \\
46.1 \%\end{array}$ & $\begin{array}{c}94.1 \% \\
5.9 \%\end{array}$ \\
\hline & & $\begin{array}{c}92.2 \% \\
7.8 \%\end{array}$ & $\begin{array}{l}77.8 \% \\
22.2 \%\end{array}$ & $\begin{array}{l}89.0 \% \\
11.0 \%\end{array}$ & $\begin{array}{c}97.5 \% \\
2.5 \%\end{array}$ & $\begin{array}{c}\mathbf{9 2 . 2} \% \\
7.8 \%\end{array}$ \\
\hline & & Risk 1 & $\begin{array}{l}\text { Risk } 2 \\
\text { Гarget Cl }\end{array}$ & $\begin{array}{l}\text { Risk } 3 \\
\text { ass }\end{array}$ & Risk 4 & \\
\hline
\end{tabular}




\section{Table 5 (on next page)}

Statistical measures for the classification test $(20 \%)$ for the four risk levels 
1

2

4

Table 5. Statistical measures for the classification test (20\%) for the four risk levels.

\begin{tabular}{ccccc}
\hline & \multicolumn{4}{c}{ Risk Levels } \\
\hline $\begin{array}{c}\text { Statistical } \\
\text { measure }\end{array}$ & $\begin{array}{c}\text { Risk } \\
\text { level 1 }\end{array}$ & Risk level 2 & $\begin{array}{c}\text { Risk } \\
\text { level 3 }\end{array}$ & $\begin{array}{c}\text { Risk } \\
\text { level 4 }\end{array}$ \\
\hline Sensitivity & $92.2 \%$ & $77.8 \%$ & $89.0 \%$ & $97.5 \%$ \\
Specificity & $98.2 \%$ & $96.8 \%$ & $96.0 \%$ & $96.6 \%$ \\
Accuracy & $98.2 \%$ & $82.7 \%$ & $96.0 \%$ & $97.3 \%$ \\
AUC & 0.961 & 0.883 & 0.971 & 0.984 \\
\hline
\end{tabular}


5

6

7

8

9

10

11

12

13 


\section{Table 6(on next page)}

Results applying different classification techniques in psychosocial factors dataset 
1

2

3

4

5

6

7

8

9

10

11

12

13

14

Table 6. Results applying different classification techniques in

\begin{tabular}{ccc} 
id & psychosocial factors dataset. *Accuracy \\
\hline Algorithm & $\begin{array}{c}\text { \% } \\
\text { classification } \\
\text { average* }\end{array}$ \\
\hline 1 & Naïv Bayes & 91.29 \\
2 & ANN & 89.71 \\
3 & SVM & 92.83 \\
5 & HC-SVM & 92.86 \\
6 & SVM-RBF & 92.86 \\
7 & KNN-SVM & 89.26 \\
9 & Robust Linear Regression & 86.66 \\
10 & Logistic Regression & 53.47 \\
11 & Proposed Method: PST-NN & 53.65 \\
12 & $\mathbf{9 7 . 3 1}$ \\
\hline \multicolumn{3}{c}{}
\end{tabular}


Figure 1

Physical surface tension-neural net

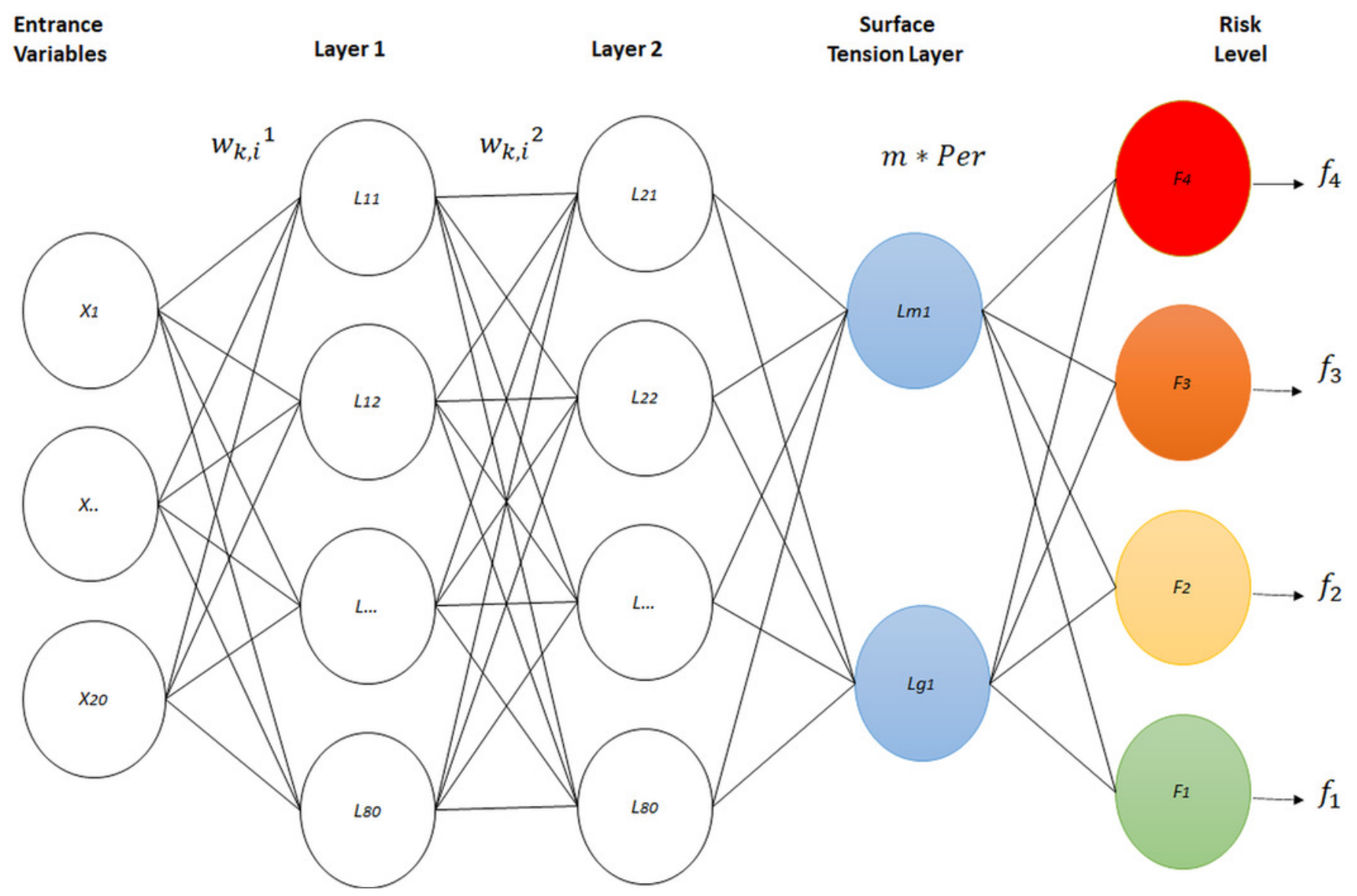




\section{Figure 2}

Classification method based on physical surface tension

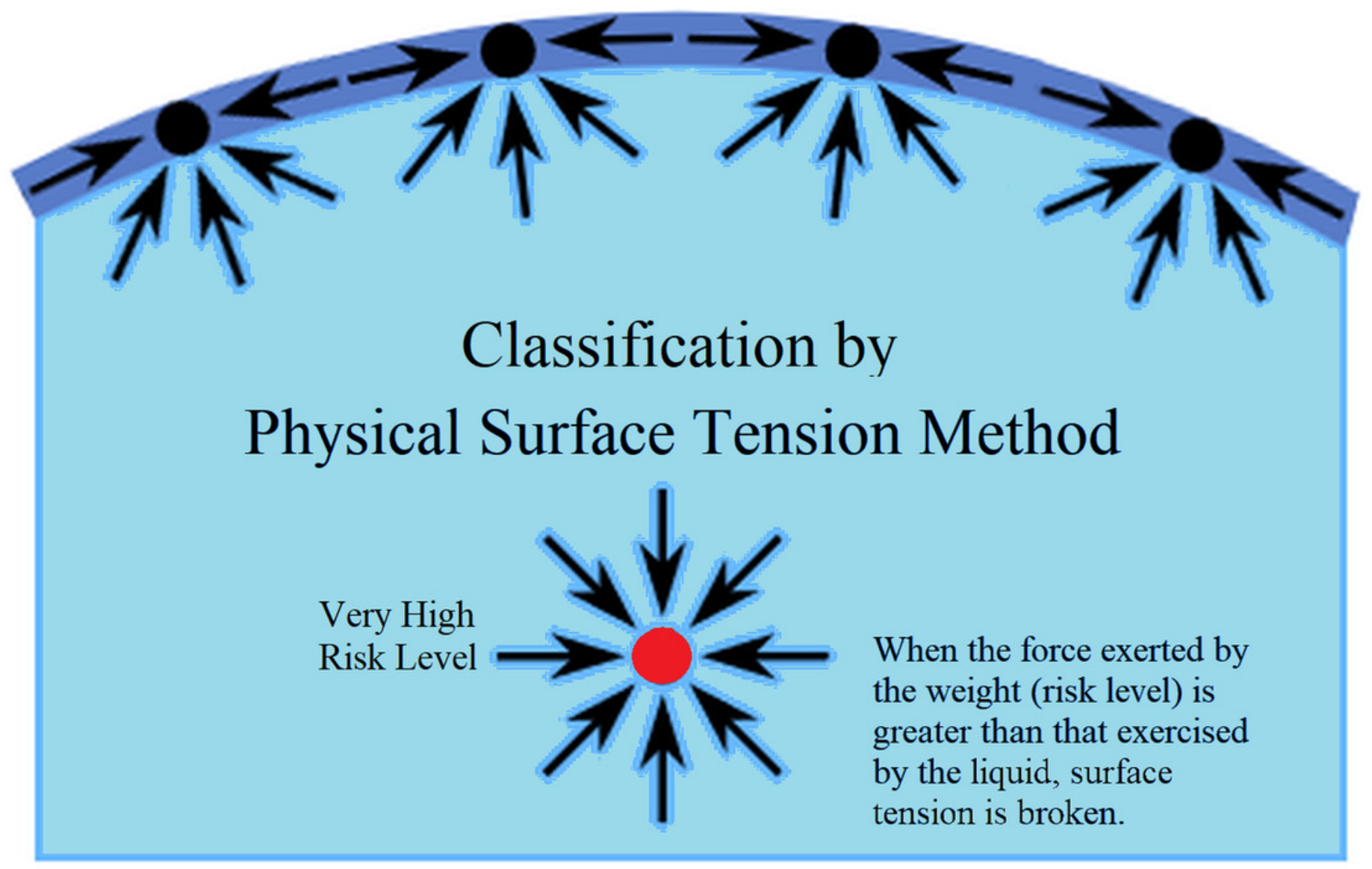


Figure 3

Iterations performance in the Physical Surface Tension-Neural Net model

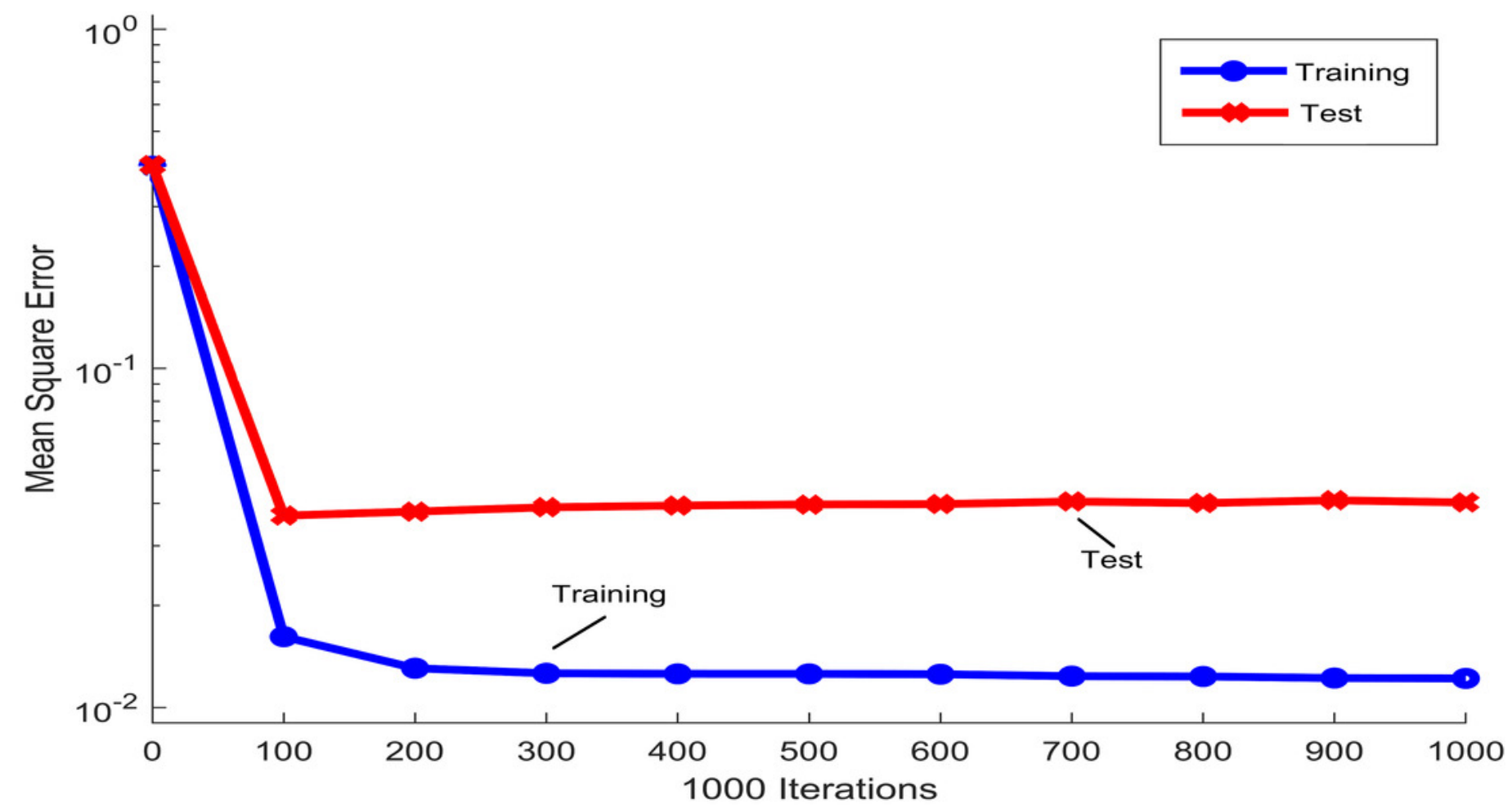


Figure 4

Mass Vs perimeter classification risk model

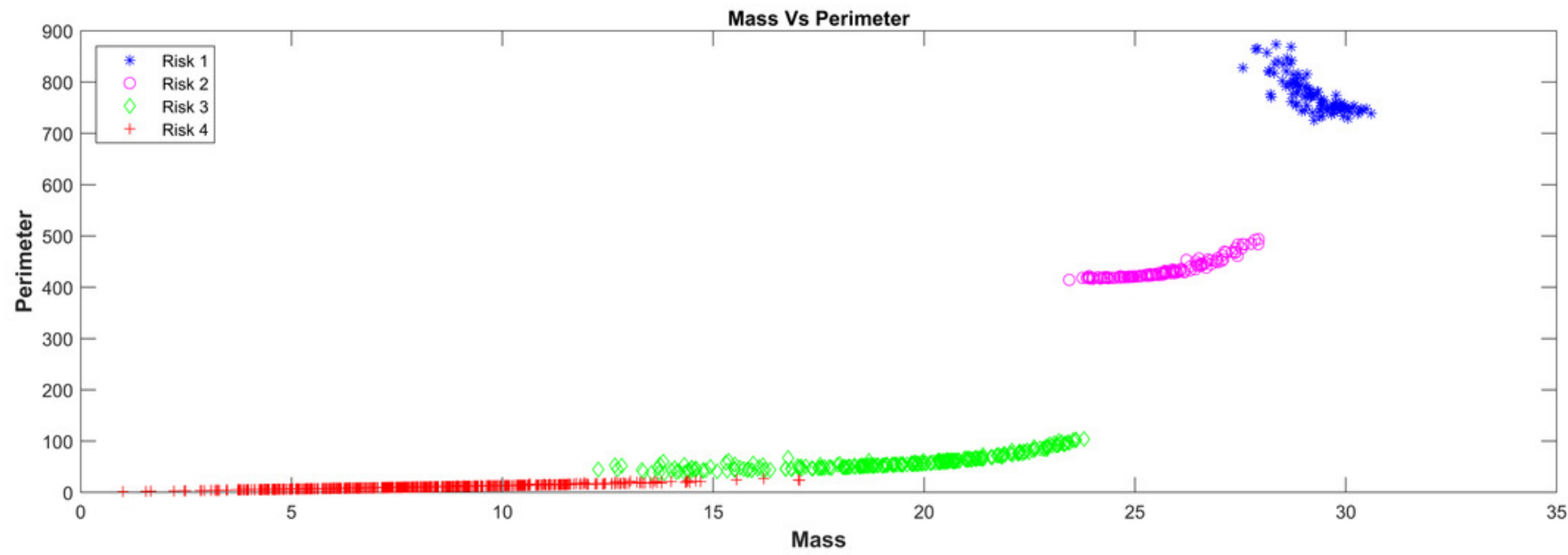


Figure 5

Visualization of risk separations in the model

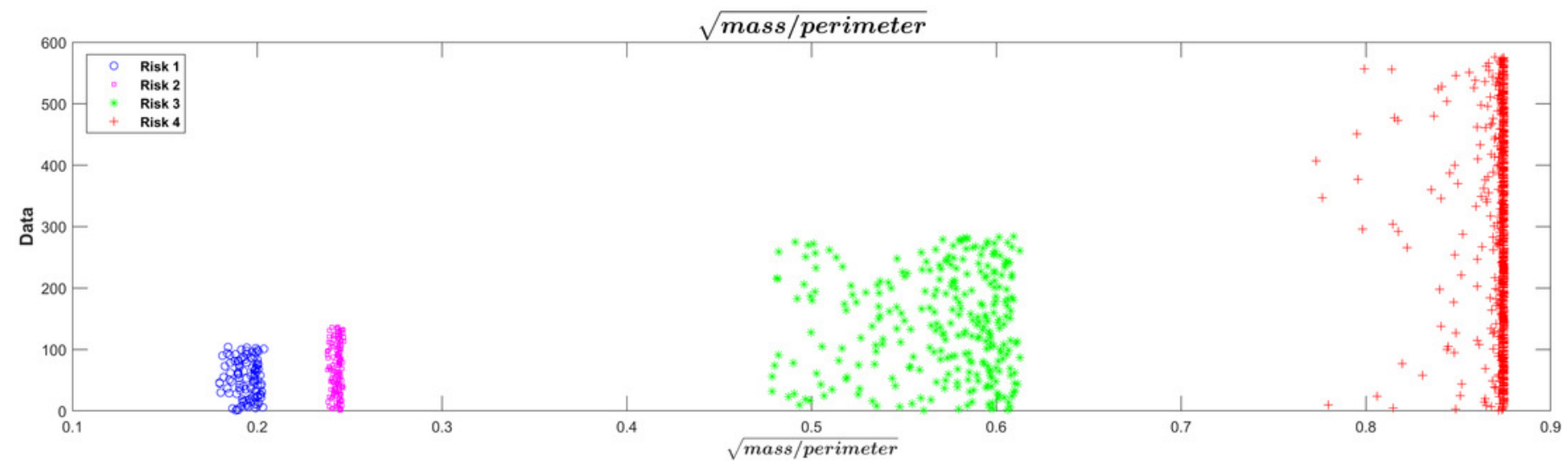


Figure 6

ROC Curve

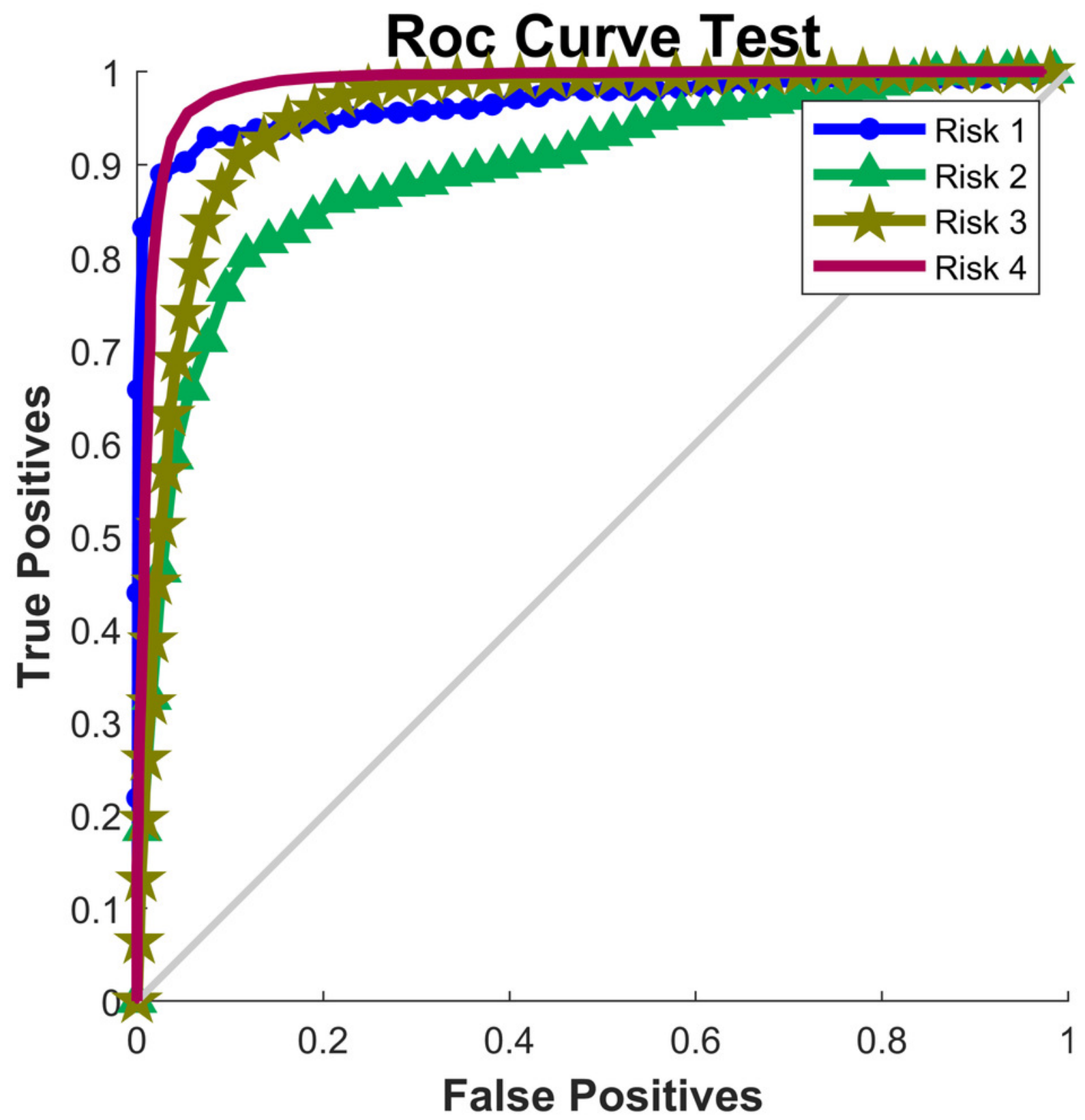

